\title{
A Comparative Study of Community-Based Diabetes Health Education between Canada and China
}

\author{
Jingjing Tang ${ }^{1}$, Rong Shi $^{1} \&$ Fan $\mathrm{Hu}^{2}$ \\ ${ }^{1}$ School of Public Health, Shanghai University of Traditional Chinese Medicine, Shanghai, China \\ ${ }^{2}$ School of Public Health, Shanghai Jiaotong UniversitySchool of Medicine, Shanghai, China \\ Correspondence: Fan Hu, School of Public Health, Shanghai Jiao Tong University School of Medicine, No.227 \\ South Chongqing Road, Shanghai, China. Tel: 86-216-384-6590.
}

Received: November 12, 2020 Accepted: June 10, 2021 Online Published: July 5, 2021

doi:10.5539/gjhs.v13n8p50

URL: https://doi.org/10.5539/gjhs.v13n8p50

\begin{abstract}
The prevalence of diabetes in the world is increasing largely, which has caused a heavy burden on the health service system of all countries. As one of the effective means of diabetes management, community-based diabetes health education has been carried weight for all over the world. Based on the practice in community-based diabetes health education, the authors compare community-based diabetes health education between Canada and China in fields of organization, approaches, personnel certification system, Using of social media, Role of pharmacist, and analyze successful experience in Canada which is worth learning. The final contribution of the paper helps to improve community-based diabetes education systems.
\end{abstract}

Keywords: A comparative study, community-based diabetes health education Canada and China, draw lessons from

\section{Introduction}

Diabetes prevalence is increasing worldwide largely as a result of improved living conditions and aging population problem. The burden of diabetes suggests urgent needs to strengthen prevention and control efforts. Chinese Government had launched Plan for Non-Communicable Disease Prevention and Treatment (2012-2015) to initially establish network of community-based diabetes management. However, the capabilities of community-based chronic disease management are still need to be strengthened.

Diabetes health education is recognized as one of the most effective interventions with less investment and higher benefit for diabetes management in the world. Compared with community-based diabetes education in China, it started early in Canada, with development of systematic theory and practice, which is worth learning from and taking for reference.

Canada and China are facing with the increasing trends in the prevalence of diabetes. The number of Canadians with diabetes increased from 1.3 million people ( $4.2 \%$ of the population) in 2000 to 2.7 million people ( $7.6 \%$ of the population) in 2010. National surveys of China conducted in 2002 and 2010 showed that the prevalence of diabetes in adults over 18 were 2.6\% (26 million people) (Li et al., 2005) and 11.6\% (113.9 million people) (Xu et al., 2013), respectively. According to IDF (International Diabetes Federation) in 2015, the prevalence of diabetes in adults aged 20-79 years were 9.5\% (2.5 million people) in Canada and 10.6\% (109.6 million people) in China ("International Diabetes Federation,"). China has the largest number of diabetics in the world.

Complications treatment which account for approximately $80 \%$ of diabetes-associated costs result in obvious economic impact. IDF had reported the economic burden of diabetes in Canada and China were respectively US $\$ 17.1$ billion and US \$51.1billion in 2015 (“International Diabetes Federation,"). Besides, diabetes is also a major health burden in terms of patients' quality of life. As the prevalence of diabetes continues to rise, economic, clinical and humanistic outcomes are likely to worsen.

It is therefore imperative that cost-effective and accessible diabetes management should be provided. Community-based Diabetes health education has been proven to be one of the most efficacious and cost-effective ways to reduce or prolong the development of diabetes complications as well as reducing the disease burden. A meta-analysis on efficacy of health education to prevent type 2 diabetes indicated that education was a useful tool in preventing diabetes (Yamaoka \& Tango, 2005). 


\section{Method}

\subsection{Sources of Data and Literature}

We collected data and literature from web of science ebsco, accessing to government open information websites, such as Canadian Public Health agency and the Canadian Diabetes Association (CDA) as well as other relevant websites. We reviewed literature, and then categorize the data and information.

\subsection{Data Processing}

We determined to compare the two countries' community-based diabetes health education from the aspects of organization, approaches, access to professionals, using of social media and role of pharmacists. We got more information by means of interviewing staff of the Canadian Diabetes Association and participating health education activities. We compared China's performance of community-based diabetes education with Canada in different aspects, and summarize experience in Canada.

\section{Results}

There are some different aspects of community-based diabetes education between Canada and China.

\subsection{Organization}

The community-based diabetes health education program involved in this article is provided by community health services both in Canada and China as public health services program. Besides government such as Centers for Disease Control and Prevention (CDC), Canada's largest Non-governmental Organization (NGO) diabetes prevention and support services organization - CDA supervises and guides the operation of the projects. The service is free across Canada to adults living with prediabetes and diabetes, as a part of the strategy of second-level prevention of diabetes. It's an effective supplement to the primary health care system in Canada. A survey carried out by a Canadian researcher indicated that patients are not quite interested in participating health education activities in clinic. The main reasons are patients are not satisfied with the appointment time, the form and content of health education, and they consider it is physicians' responsibility to treat patients. Therefore, nearly half of the family physicians will provide referral to the community-based diabetes health education programs (Gucciardi et al., 2011).

In China, Community based health education program is one of National essential public health service project, mainly carried out by the community health service center as one of its responsibility in comprehensive prevention and treatment of chronic diseases. CDC is the main administrative organization. Due to its weakness in technical and personnel aspects, health education in community health centers is usually supported by general hospitals in technical guidance and personnel training.

\subsection{Approaches}

The purpose of community-based diabetes health education in both countries is to provide people with knowledge, life skills and relevant support services that help change the behaviors and lifestyles of people living with or affected by diabetes, to modify risk factors and navigate their care and self-management. The program adopts the approaches in the forms of individual health guidance and group activities in Canada, while group education is widely adopted in China.

The author considers that individualized health guidance is the most distinctive effective approach of community-based health education in Canada. Patients can receive telephone sessions with a certified health coach and follow-up sessions to set up goals and evaluate their success. The coach will make timely adjustments according to follow-up and stage evaluation and feedback to patients. Taking their preferences and lifestyle into consideration, health coaches can help them identify and address barriers to change, and help to build decision-making, problem-solving and planning skills they need to manage their diabetes. According to the theory of healthy behavior, feedback to the target process in the control process can affect the behavior. This approach helps the person to overcome the barriers of behavior change to ensure the continuity and integrity of diabetes health education.

In addition, there are other group educational activities, which are also distinctive. (1) Learning Series delivered by trained staff and volunteers in community settings, to increase awareness of risk factors, signs, symptoms and complications of diabetes, and encourage participants to work with their health care team to prevent or manage diabetes with a healthy lifestyle. (2) Food Skills training program provides people with practical relevant guidance on how to prepare healthy meals. It developed detailed training manuals and easy-to-use participant handbooks aligned with national and provincial healthy eating guidelines and strategies. (3) Educational Events provides people with information and experiential learning opportunities, such as trade show with exhibitors that offer 
diabetes-related products and services, a cooking demonstration or lesson, dance or fitness activity, risk assessment and so on. (4) Peer education group composed of people with similar ages, cultural background and experience, with one or more facilitators and may include guest speakers share self-management experiences and address topics such as managing stress and diabetes burnout. It helps patients to improve their self-management skills and self-efficacy.

Compared with the various forms of diabetes education in Canada, there are some deficiencies in health education in China. (1) The most commonly used health education form is lectures delivered by professionals to convey information. Due to restrictions on personnel and professional level, there are not so many activities that community health centers can organize. Patients may fail to grasp skills well enough because of insufficient practice and interaction with health professionals. Besides, research shows that information alone doesn't usually result in behavior change. (2) Most of the participants of education program are diabetics in China, which leads to paying more attention to intervention and treatment rather than prevention. However, program in Canada place more emphasis on prevention, because there are 5.7 million Canadians with prediabetes, $50 \%$ of whom may progress to full diabetes. (3) Very few Chinese community centers make education plan for individuals, taking personal psychological factors, social factors, behavior patterns, cultural background, personality characteristics and other variables of impacts into consideration.

At present, health self-management group is widely implemented in Shanghai and other cities. It's a form of health education based on peer education. The group is composed of 15-20 diabetic patients, with neighborhood committee cadres as the team leader and volunteers as the Deputy group leader. Each group has a general practitioner or team to guide the group activities. In addition to professional consultation and lectures, the team members improve their health management skills through exchange, mutual supervision of individual plans implementation, mutual help to achieve better management effect.

\subsection{Health Education Personnel Certification System}

Canada has implemented the health education personnel certification system for eligible health professionals who are currently practicing in diabetes education in Canada since 1991. Certification as a diabetes educator recognizes experience and excellence in diabetes education and verifies that an individual possesses the knowledge, skills and abilities to practice effectively and safely within their professions' scope of practice. This system ensures the quality of diabetes health education. According to the Canadian Standards for Diabetes Education, each candidate must be fully registered and licensed with a regulatory body in Canada as a health professional and have worked a minimum of 800 hours of practice in diabetes education. After successfully completing the Canadian Diabetes Educator's Certification Board (CDECB) exam, they are certificated as health educators credential for a period of 5 years. Thereafter, Certification Maintenance is available by examination or by credit portfolio option, which requires 250 credits accumulated over a five-year period obtained from a wide list of diabetes related continuing education activities ("Canadian Diabetes Education Certification Board. How to become a CDE").

There are mainly healthcare workers, especially nurses act as diabetes health education practitioners in Chinese community health centers. Due to the late start of "health education" in China, most health educators never received systematical theoretical and practical health education training. Their health education guidance lacks theoretical basis. The Chinese government doesn't establish certification system and standardized training system for health educators. There aren't sufficient professional educators with adequate theoretical knowledge, which affect the quality of health education.

\subsection{Using of Social Media}

Web-based social media is widely used across Canada and China. The Internet offers opportunities for education information delivery and peer support. CDA advertises the program on Facebook, delivering information of activities by email to increase outreach or hosts an online workshop or webinar for interaction between diabetes participants and experts. Western scholars, Fox \& Purcell2010, point out that internet media are increasingly attractive to patients with chronic diseases who seek support from blogs and online discussions ("Chronic disease and the Internet,").

Email in China is not as popular as in Canada, while digital and mobile technology is fast developing in China. More and more new media tools are used in health education, such as health APP for self-monitoring, nutrition guidance and physical exercises, WeChat for group communication between educators and patients, as well as peer group communication. However, privacy and security remain a concern.

\subsection{Role of Pharmacist}

Involvement of a pharmacist in diabetes health education results in improving medication compliance and diabetes 
related self-efficacy, as well as appropriate self-care behavior (Rosin \& Townsend, 2008). There's Community Pharmacy Outreach Program (CPOP), which is a collaborative partnership between CDA and pharmacies to help better support people living with diabetes. Pharmacists provide information about medications, upcoming events and programs of CDA. They also offer support and advice to manage diabetes.

In China, there are few clinical pharmacists in community health centers because most of communities are only equipped with essential drugs. People are used to going to the general hospital to get medicine. Pharmacists in community health service centers have not enough participation and cannot make efforts as expected.

\section{Discussion}

To summarize Canada's success in health education, I would include the following.

\subsection{The Government Plays an Important Role in Health Education and Health Promotion Development}

Health education has a long history in Canada. As early as 1880s, the Canadian government started health education through traditional media to spread health information. With the emergence of health behavior theory in 1970s, health education was further developed and divided into two levels: "doctor-patient" and "health education expert - social public". With the government's awareness of the prevalence of chronic diseases and the identification of health priorities, health education established its important position.

In 1970s, the concept of health education was further extended to health promotion, emphasizing health promotion through education and environmental support. In 1974," A New Perspective on the Health of Canadians (Lalonde, 1974)" released, focusing on influence of environment and lifestyle on health. It is the first official document of western country that vigorously advocated "health promotion" as an important strategy to improve public health, rather than traditional disease treatment model. Canada also hosted the first international conference on health promotion in Ottawa in collaboration with the World Health Organization in 1976. The conference produced Ottawa Charter and Canadian government released its own discussion paper Achieving Health for All: A Frame Work for Health Promotion. Since then, Canada had been acknowledged and respected as a leader in health education and health promotion for 2 decades.

In recent years, the Chinese government has paid more attention to health education to cope with chronic diseases. The outline of Health China 2030 strategy clearly proposes to improve the public health system and strengthen health education. Health education is carried out as a national basic public health service project.

\subsection{Construction of Service Network}

Canadian government established management system and service network to ensure implement of health education and health promotion. The Canadian government established a Health Promotion Directorate within the federal Department of National Health and Welfare, which is the first bureaucratic structure devoted to health promotion in the world. The years immediately following the release of the Ottawa Charter, Provincial governments re-organized their bureaucratic structures to include health promotion and funded a series of health promotion projects at the provincial and community level. Health and social service organizations, such as public health units and community health centers, began staffing positions as "health promoters" ("Public Health Ontario. Health Promotion, Chronic Disease and Injury Prevention"). Besides, NGO, such as the Canadian Diabetes Association, provincial public health association and health promotion association, etc. also played important roles. Because of the wide distribution of the service network, it is easy for people living with diabetes to find a health educational resource to access.

\subsection{Community-Based Foundation}

Clinical and hospital-based health education pays more attention to one-way delivery of the knowledge and skills, which leads to defect in mobilizing the enthusiasm of patients to take part in the program. However, community-based program which motivate patients and their family to participate in, reflects one of the basic principles of health education and health promotion as "community empowerment". It highlights respect to the values, knowledge, culture and community decision-making on the basis of needs assessment of the individuals and groups in the community whilst developing the skills and resources they have to meet their own needs. Compared with the clinical and hospital-based model, it is a important strategy which provides much more abundant resources and various forms of activities, aiming to empower people to gain control over the risk factors influencing their health.

\subsection{Combined with Voluntary Service System}

Diabetes educators are insufficient even in Canada because of the large number of patients with diabetes. Previous studies have shown that enrollment of volunteers make up for a lack of human resources, reduce the cost and 
improve effectiveness of the interactions with participants and improve the health behaviors of the volunteers themselves (Moore, 2002). The reasons for the integration are mainly:

Firstly, the history, the mission and organizational culture, advocate volunteers to participate. The CDA's predecessors, are those volunteers who served people living with diabetes. So far, there are more than 30000 volunteers in CDA across Canada. Secondly, there's a standardized management system, including volunteer recruitment, training, assignment of tasks and the role of position. Government set up national awards to recognize outstanding contributions in diabetes management service. In addition, voluntary atmosphere and the spirit has been rooted in social values. Most of the volunteers contribute themselves to society out of gratitude and some local high school students need volunteer service experience when they apply for college or occupation.

In the past 20 years, the voluntary service system is gradually developing and improving in China.

Most general hospitals have established social work departments. However, it still needs to develop in communities.

\subsection{Construction of Community Supportive Environment}

The health education theory has its limitations, as it emphasizes "personal skills", while ignoring the influence of environment on health and personal behavior. However, according to the theory of health ecological model, individual behavior is not only influenced by individual level factors, but also influenced by interpersonal and social environment factors (O'Neill, Pederson, Rootman, \& Dupéré, 2007). In order to make up for the deficiency of health education, the government construct community supportive environment for people's better choice of health behavior.

This strategy includes three aspects: Firstly, fostering a supportive social network to build community capacity and enhance self-efficacy. Secondly, constructing supportive physical environment, such as building community facilities for exercises. Thirdly, establishing and strengthening the supportive policy environment, such as financial policy and legislation of food nutrition labels.

\section{Conclusion}

The Canadian community-based diabetes Health Education started early, with solid foundation of society, sound management system as well as administrative organization and community network legislated by law. Qualified health education professionals and well-trained volunteers provide services with various forms of individual and group education activities on the basis of mature health education theory, which mobilize the enthusiasm of the participants. Canada attaches great importance to the construction of supportive environment, making up for the lack of health education.

Community-based diabetes education in China is improving, but more resources are need to achieve a nationally better service.

1) The government should formulate supportive policies and local regulations and establish management organization system which Includes leadership and guidance by health administrative department as well as coordination and intervention by local government.

2) National finance should ensure the investment of health education funds, besides, seeking more investment channels, such as the insurance industry to increase funding.

3) It's important to strengthen and complete continual education and training system for development of health education professionals. First of all, we need to establish national and local health education and health promotion institutions as community health education guidance centers which are responsible for program planning, implementation and evaluation as well as personnel training. Furthermore, educator access system should be set up in the future to ensure the qualifications of employees.

4) Educators should strengthen application of the theories of "community empowerment" and "community development" with other health behavior theory when they provide services to elevate the activeness of the participants, and it's helpful for improving self-efficacy as well as appropriate health behavior.

5) Learning from diabetes health education forms offered by CDA, Chinese community health service centers should adopt the forms that integrates individual guidance and group activities with technical support from general hospitals. More prevention educational activities should be offered, aiming at potential and prediabetes. Social worker and volunteer service system need to be established to make up for the shortage of professionals. 


\section{Acknowledgements}

Grant: The Fourth Round of Shanghai Public Health Three-Year Action Plan Key Discipline Construction-Health Education and Health Promotion (Grant No. 15GWZK1002).

I would like to thank the professor David Zakus, for his help with my investigation of diabetes health education in Canada when I work as a visiting scholar in Toronto.

\section{Competing Interests Statement}

The authors declare that there are no competing or potential conflicts of interest.

\section{References}

Canadian Diabetes Education Certification Board. How to become a CDE. Retrieved from http://www.cdecb.ca/what-is-a-cde-/how-to-become-a-cde/

Chronic disease and the Internet. Retrieved http://pewinternet.org/Reports/2010/Chronic-Disease/Summary-of-Findings.aspx/

Gucciardi, E., Chan, V. W.-S., Fortugno, M., Khan, S., Horodezny, S., \& Swartzack, S. J. (2011). Primary Care Physician Referral Patterns to Diabetes Education Programs in Southern Ontario, Canada. Canadian Journal of Diabetes, 35(3), 262-268. https://doi.org/10.1016/S1499-2671(11)53009-6

International Diabetes Federation. Retrieved from http://www.idf.org.

Lalonde, M. J. w. p.-a. g. c. p.-s. p. p. p. p. (1974). A new perspective on the health of Canadians.

Li, L. M., Rao, K. Q., Kong, L. Z., Yao, C. H., Xiang, H. D., Zhai, F. Y., ... \& Yang, X. G. (2005). A description on the Chinese national nutrition and health survey in 2002. Zhonghua liu xing bing xue za zhi=Zhonghua liuxingbingxue zazhi, 26(7), 478-484.

Moore, K., \& Mengol, M. (2002). Expanding the team: the use of volunteers in a diabetes education program. The Diabetes Educator, 28(4), 554-562. https://doi.org/10.1177/014572170202800409

O'Neill, M., Pederson, A., Rootman, I., \& Dupéré, S. (2007). Health promotion in Canada: critical perspectives. Canadian Scholars' Press.

Public Health Ontario. Health Promotion, Chronic Disease and Injury Prevention. Retrieved from http://www.publichealthontario.ca/en/About/Departments/Pages/Health-Promotion-Chronic-Disease-InjuryPrevention.aspx\#.VymyY-x7IzB/.

Rosin, J., \& Townsend, K. (2008). Intervention and education in diabetes: a pilot project comparing usual care with pharmacist-directed collaborative primary care. Canadian Pharmacists Journal/Revue des Pharmaciens du Canada, 141(6), 346-351. https://doi.org/10.3821/1913-701X-141.6.346

Xu, Y., Wang, L. M., He, J., Bi, Y. F., Li, M., Wang, \& T. G., ... \& China Noncommunicable Dis, S. (2013). Prevalence and Control of Diabetes in Chinese Adults. Jama-Journal of the American Medical Association, 310(9), 948-958. https://doi.org/10.1001/jama.2013.168118

Yamaoka, K., \& Tango, T. (2005). Efficacy of lifestyle education to prevent type 2 diabetes - A meta-analysis of randomized controlled trials. Diabetes Care, 28(11), 2780-2786. https://doi.org/10.2337/diacare.28.11.2780

\section{Copyrights}

Copyright for this article is retained by the author(s), with first publication rights granted to the journal.

This is an open-access article distributed under the terms and conditions of the Creative Commons Attribution license (http://creativecommons.org/licenses/by/4.0/). 